\title{
Isolation of Laminaria-frond Decomposing Bacteria from Japanese Coastal Waters
}

\author{
Motoharu Uchida* and Akihiko Nakayama* \\ (Received June 4, 1993)
}

\begin{abstract}
A search was undertaken to isolate bacteria capable of decomposing Laminaria fronds directly. Among 89 strains isolated from seawater samples with an agar plate enriched with Laminaria powder, 62 strains showed a Laminaria-frond decomposing ability which was detected by a rheometer test after 4 weeks' incubation at $20^{\circ} \mathrm{C}$. The Laminaria-frond decomposing bacteria (LDB) were isolated from 10 locations out of 11 , suggesting their widespread distribution in the Japanese coastal waters. Most of the LDB were assigned to the Vibrio group according to Simidu's scheme and had an alginate-degrading ability. $\mathrm{Gel}$ filtration analysis of saccharides dissolved in the culture medium during the decomposition test showed that the algal polysaccharides were degraded, and that the decomposition products differed greatly in molecular size from strain to strain.
\end{abstract}

It is generally accepted that microbial decomposition plays a great part in the decay process of macrophytic brown algae in the marine environment. ${ }^{1-3)}$ Research on the microbial decomposition of macroalgae elucidated an increase in the numbers of bacteria capable of utilizing algal substances not only on the surface of decaying fronds $s^{1}$ but also in water associated with algal vegetation." Especially, bacteria able to degrade alginate compounds which are one of the major components of brown algae have been isolated by many researchers. ${ }^{4-18)}$ The authors are interested in bacteria which have a frond-decomposing ability not only from a bacteriological point of view but also for the reason that microbial decomposition of macroalgae contributes greatly to the detrital food chain in the marine ecosystem. ${ }^{17}$ But an investigation on bacterial isolates with an ability to decompose macroalgal fronds directly $y^{2,18}$ is limited. This is partly attributed to the reason that there was no good method for estimating the decomposing activity for macroalgal fronds besides the method of measuring their weight losses. ${ }^{1-3)}$

In this study, we developed a method for estimating the frond decomposition activity by use of a rheometer, and attempted to isolate bacteria which have the ability to decrease the physical strength of frond issue of brown alga Laminaria iaponica from Japanese coastal waters. We called them Laminaria-frond decomposing bacteria.
(LDB) and examined their bacteriological characteristics including a test for their alginate-degrading ability. Saccharide substances remaining after the frond decomposition test were analyzed by gelfilltration for some strains to elucidate the mode of decomposition processes.

\section{Materials and Methods}

Laminaria-fronds

Damp-dried fronds of Laminaria japonica, kombu, harvested off Hakodate were obtained. To prepare the isolation medium, fine Laminaria powder (200-mesh) made by milling the dampdried fronds was used. Square pieces of frond $(1.5 \times 3.0 \mathrm{~cm}, 0.4-0.5 \mathrm{~g}$ dry weight $)$ taken from a part between 30 and $100 \mathrm{~cm}$ from the basal part (Fig. 1) were used for a frond decomposition test.

\section{Samples of Seawater}

Samples of seawater were taken separately in a sterilized bottle at 11 locations (Table 1) off the coast of Japan between June 13th and August 11th, 1987. The seawater, cooled with ice, was brought to our laboratory and used for bacterial isolation. The water temperature was measured in situ, and $\mathrm{pH}$ and salinity were determined at the laboratory. The viable counts were determined on the following isolation medium.

* National Research Institute of Fisheries Science, Fisheries Agency, Fukuura, Kanazawa, Yokohama 236, Japan（内田基晴，中山昭彦：水厘打中央水限研究所）. 


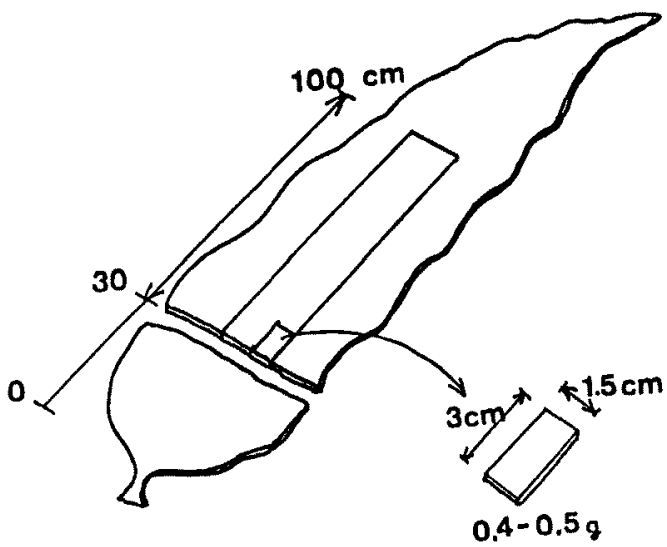

Fig. 1. Diagram showing the preparation of Laminaria frond (damp-dried Laminaria japonica: kombu) pieces for a frond-decomposition test.

Isolation of Bacteria with Laminaria PowderEnriched Agar Plate

One milliliter each of the serial dilutions of the seawater sample was plated out with $10 \mathrm{ml}$ of an upper medium: $10 \%$ Laminaria powder, $90 \%$ aged natural seawater, $1.5 \%$ agar $(\mathrm{pH} 7.6)$, which was laid on $10 \mathrm{ml}$ of a lower medium: $90 \%$ aged natural seawater, $1.5 \%$ agar (KSA medium). After incubation at $20^{\circ} \mathrm{C}$ for $8-20$ days, single colonies with good growth and/or hollow formation were picked up and purified on agar plates containing $0.5 \%$ pepton, $0.3 \%$ beef-extract, $1.5 \%$ agar, and $90 \%$ aged natural seawater (NAS medium). All isolates were subject to the following frond decomposition test.

\section{Test for Frond Decomposing Ability}

A loopful of 3-7-day-old precultures of each strain on the NAS slant was inoculated into two kinds of $50 \mathrm{ml}$ medium: one known as S-medium consisting of 2 frond pieces and $90 \%$ aged natural seawater ( $\mathrm{pH}$ 6.9), and the other known as NSmedium made up of 2 frond pieces, $0.5 \%$ pepton, $0.3 \%$ beef-extract, and $90 \%$ aged natural seawater (pH 6.8). After 4 weeks' incubation at $20^{\circ} \mathrm{C}$ on a reciprocal shaker $(70 \mathrm{rpm})$, frond pieces were taken out and cut into strips $10 \mathrm{~mm}$ in width. Cutting strength was measured 5 times for each piece with a rheometer using a plunger of steel wire (Fig. 2). The average value of the two pieces was calculated to determine the frond decomposing ability.

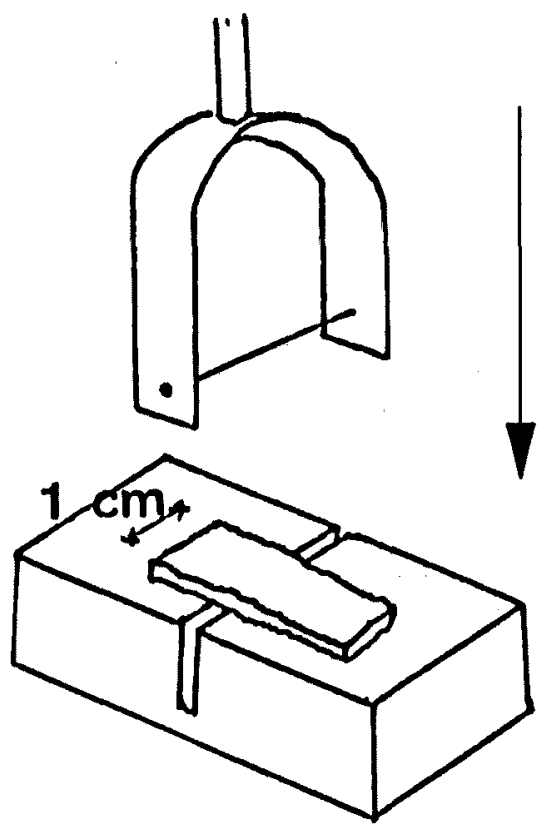

Fig. 2. Diagram of a rheometer test equipped with a plunger of steel wire.

\section{Characterization of Isolates}

The bacterial isolates were identified according to the scheme of Simidu. ${ }^{18)}$ All the isolates were examined for cell shape, gram reaction, motility, catalase activity, oxidase activity, and sensitivity to $\mathrm{O} / 129$ phosphate. An O/F test was carried out with a marine oxidation-fermentation medium proposed by Leifson. ${ }^{20}$ The ability to degrade sodium alginate was determined by AndoInoue's method. ${ }^{\text {) }}$ Isolates were inoculated on to an aga $\mathrm{r}$ plate consisting of $1 \%$ sodium alginate, $3.5 \% \quad \mathrm{NaCl}, \quad 0.5 \% \quad\left(\mathrm{NH}_{4}\right)_{2} \mathrm{SO}_{4}, \quad 0.2 \% \quad \mathrm{~K}_{2} \mathrm{HPO}_{4}$, $0.1 \% \mathrm{MgSO}_{4} \cdot 7 \mathrm{H}_{2} \mathrm{O}, 0.001 \% \mathrm{FeSO}_{4} \cdot 7 \mathrm{H}_{2} \mathrm{O}, 1.5 \%$ agar plate $\left(\mathrm{pH} \mathrm{7.2)}\right.$, and incubated at $20^{\circ} \mathrm{C}$ for 7 days. The ability of alginate-degradation was judged by hollow formations around colonies. Halophilic tests were conducted by comparing the growth in ZoBell $2216 \mathrm{E}$ medium with that in the same medium but prepared with distilled water.

\section{Gel Filtration of Solubilized Saccharides in the Culture Meditum}

The culture medium remaining after the fronddecomposition test were centrifuged at $8000 \mathrm{rpm}$ for 20 minutes. The supernatant was filtrated through a $0.22 \mu \mathrm{m}$ mesh. The filtrate $(5 \mathrm{ml})$ was applied to a Sephacryl S-300 column $2.6 \times 96 \mathrm{~cm}$, 
Table 1. Details of seawater samples

\begin{tabular}{|c|c|c|c|c|c|c|}
\hline \multicolumn{2}{|l|}{ Sampling } & \multirow{2}{*}{ Symbols } & \multirow{2}{*}{$\underset{\left({ }^{\circ} \mathrm{C}\right)}{\text { Temp. }}$} & \multirow{2}{*}{$\mathrm{pH}$} & \multirow{2}{*}{$\underset{(\% 0)}{\text { Salinity }}$} & \multirow{2}{*}{$\begin{array}{l}\text { Viable counts } \\
\qquad(\mathrm{CFU} / \mathrm{m} l)\end{array}$} \\
\hline Locations & Date & & & & & \\
\hline Yokosuka, Kanagawa & 870613 & $\mathrm{AR}$ & - & - & 33.9 & $1.0 \times 10^{3}$ \\
\hline Shimizu, Shizuoka & 870721 & EN & 26.5 & 8.3 & 29.8 & $2.2 \times 10^{5}$ \\
\hline Hakodate, Hokkaido & 870720 & $\mathrm{HA}$ & - & 8.3 & 32.9 & $2.2 \times 10^{4}$ \\
\hline Kushiro, Hokkaido & 870714 & HO & 12.7 & 8.3 & 32.5 & $4.6 \times 10^{2}$ \\
\hline Yosa, Kyoto & 870714 & KY & 23.7 & 8.2 & 33.8 & $2.3 \times 10^{3}$ \\
\hline Saeki, Hirosima & 870730 & NA & 26.8 & 8.5 & 24.2 & $4.3 \times 10^{4}$ \\
\hline Niigata, Niigata & 870722 & NI & - & 8.2 & 24.0 & $9.8 \times 10^{2}$ \\
\hline Hirado, Nagasaki & 870804 & $\mathrm{SE}$ & 25.3 & 8.3 & 33.6 & $1.5 \times 10^{2}$ \\
\hline Shimonoseki, Yamaguchi & 870803 & SU & 38.0 & 8.6 & 32.8 & $8.0 \times 10^{4}$ \\
\hline Miyagi, Miyagi & 870713 & TO & 20.0 & 8.3 & 32.2 & $1.0 \times 10^{3}$ \\
\hline Watarai, Mie & 870811 & YO & 26.8 & 8.3 & 33.8 & $1.8 \times 10^{2}$ \\
\hline
\end{tabular}

* Counted on KSA agar plate $(2 \%$ Laminaria powder, $90 \%$ aged natureal seawater and $1.5 \%$ agar $)$.

and eluted with $0.025 \mathrm{M}$ sodium phosphate $(\mathrm{pH}$ 7.0) at a flow rate of $0.6-1.0 \mathrm{~m} l / \mathrm{min}$. Every $5 \mathrm{~m} l$ fraction was collected. The saccharide content in the fractions was measured according to the modified Carvazole-sulfulic acid method. ${ }^{21}$ ) A medium with no bacterial inoculation was used as the control.

\section{Results}

Isolation of Bacteria with Laminaria PowderEnriched Agar Plate

Details of seawater smaples are given in Table 1. The salinity and $\mathrm{pH}$ were within the normal range, but only the samples taken at Saeki (NA) and Niigata (NI) had a low salinity of $24 \%$. Viable counts on KSA plates ranged from $10^{2}$ to $10^{5} \mathrm{cfu} / \mathrm{ml}$. Some colonies formed clear hollows.

About 8 colonies with good growth and/or hollow formation were picked up for each location. In all 89 strains were isolated.

\section{Test for Frond Decomposing Ability}

The isolated 89 strains were tested for frond decomposing ability using two kinds of medium. The Laminaria frond pieces in the medium were autoclaved before the decomposition test, but hardly changed in their outer appearance or physical strength. In some cases, the frond pieces gradually decayed and lost their squarish appearance, followed by their partial fragmentation during incubation. To estimate the overall ability to decompose the frond piece, the decreasing physical strength of the frond piece was followed by measuring the cutting strength with a rheometer. As shown in Fig. 3, the cutting strength measured after 4 weeks' incubation with bacteria ranged
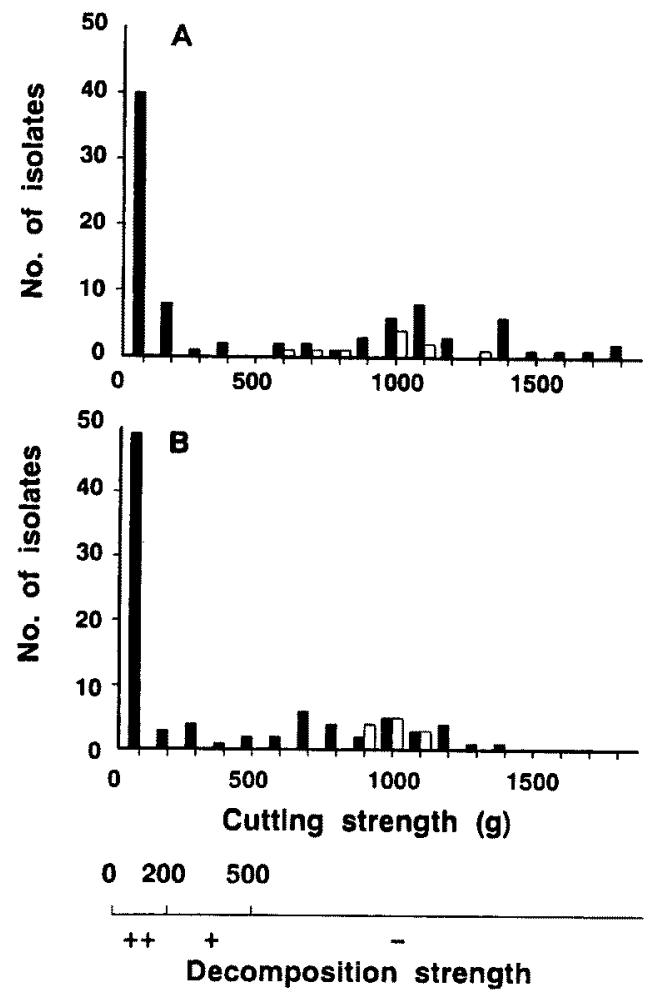

Fig. 3. Distribution of cutting strength of Laminaria frond pieces after the decomposition test.

A, in S-medium (two frond pieces in $90 \%$ aged natural seawater) and $B$, in NS-medium (two frond pieces in $90 \%$ aged natural seawater, $0.5 \%$ beef extract, and $0.3 \%$ polypepton) with bacterial inoculation (closed bar, $n=89$ ) and without inoculation (open bar, $n=10$ ). Cutting strengts of $0-200,201-500$, and $>500 \mathrm{~g}$ were tentatively defined as decomposition strength,++ , and - , respectively. 
Table 2. Numbers of isolates having a decomposing ability for Laminaria frond in $\mathrm{S}$ and NS medium

\begin{tabular}{|c|c|c|c|c|}
\hline & & \multicolumn{3}{|c|}{$\begin{array}{l}\text { Frond-decomposing } \\
\text { ability in NS } \\
\text { medium*** }\end{array}$} \\
\hline & & $\neq^{*}$ & $f^{*}$ & -* \\
\hline Frond-decomposing & $H^{*}$ & 41 & 1 & 5 \\
\hline ability & $t^{*}$ & 4 & 0 & 0 \\
\hline in $S$ medium** & $-^{*}$ & 7 & 4 & 27 \\
\hline
\end{tabular}

* Decomposition,++ , and - means cutting strength 0 $200,201-500$, and $>500 \mathrm{~g}$, respectively.

* Two Laminaria frond pieces in $90 \%$ aged natural seawater.

*** Two Laminaria frond pieces in $0.5 \%$ pepton, $0.3 \%$ beefextract, and $90 \%$ aged natural seawater.

Table 3. Number of isolates having a Laminaria frond decompositing ability and a hollow forming ability on KSA plate

\begin{tabular}{|c|c|c|}
\hline & \multicolumn{2}{|c|}{$\begin{array}{l}\text { Hollow forming } \\
\text { ability on } \mathrm{KSA}^{*}\end{array}$} \\
\hline & Positive & Negative \\
\hline \multirow{2}{*}{$\begin{array}{l}\text { Frond-decomposing } \\
\text { ability }\end{array}$} & 53 & 9 \\
\hline & 25 & 2 \\
\hline \multicolumn{3}{|c|}{ - $2 \%$ Laminaria powder, $90 \%$ seawater, and $1.5 \%$ agar. } \\
\hline \multicolumn{3}{|c|}{$\begin{array}{l}\text { ** Frond decomposing ability is positive in either ( } S \text { or NS } \\
\text { medium. }\end{array}$} \\
\hline \multicolumn{3}{|c|}{$\begin{array}{l}\text { *** Frond decomposing ability is negative in both (S and NS) } \\
\text { media. }\end{array}$} \\
\hline
\end{tabular}

from 10 to $1,750 \mathrm{~g}$, while that of an axenic control was distributed between 500 and $1,300 \mathrm{~g}$. We tentatively defined cases giving a cutting strength of $0-200,201-500$, and $>500 \mathrm{~g}$ as marked decomposition $(H)$, weak decomposition $(+)$, and no decomposition (-), respectively. Fifty one of the 89 strains showed decomposing ability in the Smedium, and 57 in the NS-medium, while in total 62 of the 89 strains showed the ability in either medium (Table 2). However, not all of the strains which formed a hollow on the KSA plate decomposed the frond pieces; of the 78 strains which formed hollows, 25 did not decrease the cutting strength at all, while on the contrary, of the 11 strains which did not form hollows, 9 decomposed the frond pieces (Table 3). This indicates that the hollow is not always a useful marker for Laminariafrond decomposing bacteria. The presence of LDB was found in the seawater taken at 10 of the 11 locations (Fig. 4).

\section{Characteriaztion of Isolates}

The isolated 89 strains were tested for identification according to Simidu's scheme (Table 4). All of the isolates were gram-negative and rod bacteria,
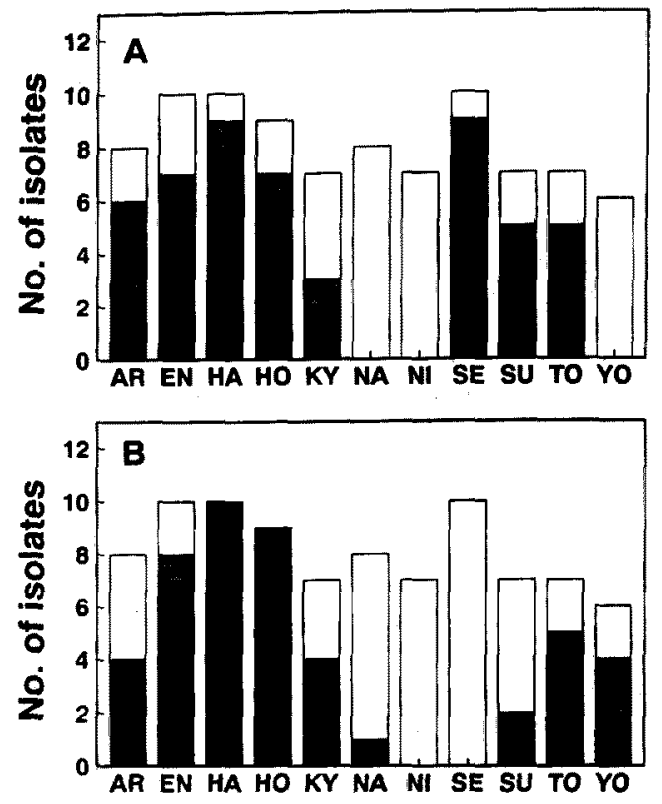

\section{Sampling locations}

Fig. 4. Numbers of Laminaria frond-decomposing bacteria isolated at 11 locations in $\mathrm{S}$ medium (A) and NS-medium (B).

Bacteria showed marked decomposition (closed bar), weak decomposition (crossed bar), and no decomposition (open bar). See Table 1 for the symbols of sampling locations.

and were categorized into 3 groups. Of the 89 strains, $84(94 \%)$ were identified as Vibrio (Group I), three as Aeromonas (Group II), and two as Pseudomonas or Cytophaga (Group III). It is noteworthy that $61(98 \%)$ of the isolated 62 LDB strains were grouped into Vibrio, which corresponds to $73 \%$ of the total of 84 Vibrio strains isolated (Table 5).

All of the isolates were also tested for alginatedegrading ability, since alginate is the major structural material of the Laminaria-frond tissue. As seen in Table 6, there was a good correlation between Laminaria-frond decomposing ability and alginate-degrading activity: 48 of the 62 LDB strains formed hollows on alginate-enriched agar plates, whereas only one of the 27 non-LDB strains did.

Gel Filtration of Saccharides Solubilized from Laminaria-frond along with Frond Decomposition

It was supposed that the decrease in physical strength of the Laminaria-frond was attributed to the degradation of structural polysaccharides such 
Table 4. Bacteriological characteristics of isolates

\begin{tabular}{cccccccccc}
\hline Group & $\begin{array}{c}\text { Gram } \\
\text { stain }\end{array}$ & $\begin{array}{c}\text { Cell } \\
\text { shape }\end{array}$ & Pigment & OF & Oxidase & O/129 & Halophilic & Motility & Numbers \\
\hline I & - & Rod & C/Y/B & F & + & S & H & $+/-$ & 82 \\
& - & Rod & C & F & - & S & H & + & 1 \\
II & - & Rod & C & F & - & S & H T & - & 1 \\
III & - & Rod & C/Y & F & + & R & H & $+1-$ & 3 \\
\hline Symbols: & +, positive; -, negative; C, cream-white; Y, yellow-orange; B, blue-black; F, fermentative; S, sensitive; R, resistant; \\
According to the Simidu's scheme, group I, II, and III is assigned to the genus Vibrio, Aeromonas, and Psendomonas or Cytophaga, \\
respectively.
\end{tabular}

Table 5. Grouping of isolates and their frond decomposing ability

\begin{tabular}{llcc}
\hline & & \multicolumn{2}{c}{ Frond-decomposing ability } \\
\cline { 3 - 4 } & & $H /+^{* *}$ & - $^{* * *}$ \\
\hline Group $\mathrm{I}^{*}$ & 61 & 23 \\
Group $\mathrm{II}^{*}$ & 1 & 2 \\
Group $\mathrm{III}^{*}$ & 0 & 2 \\
\hline
\end{tabular}

* According to the Simidu's scheme, Group I, II, and III are assigned to the genus Vibrio, Aeromonas, and Psettdomonas or Cytophaga, respectively.

** Frond decomposing ability is positive in either (S or NS) medium.

*** Frond decomposing ability is negative in both (S and NS) media.
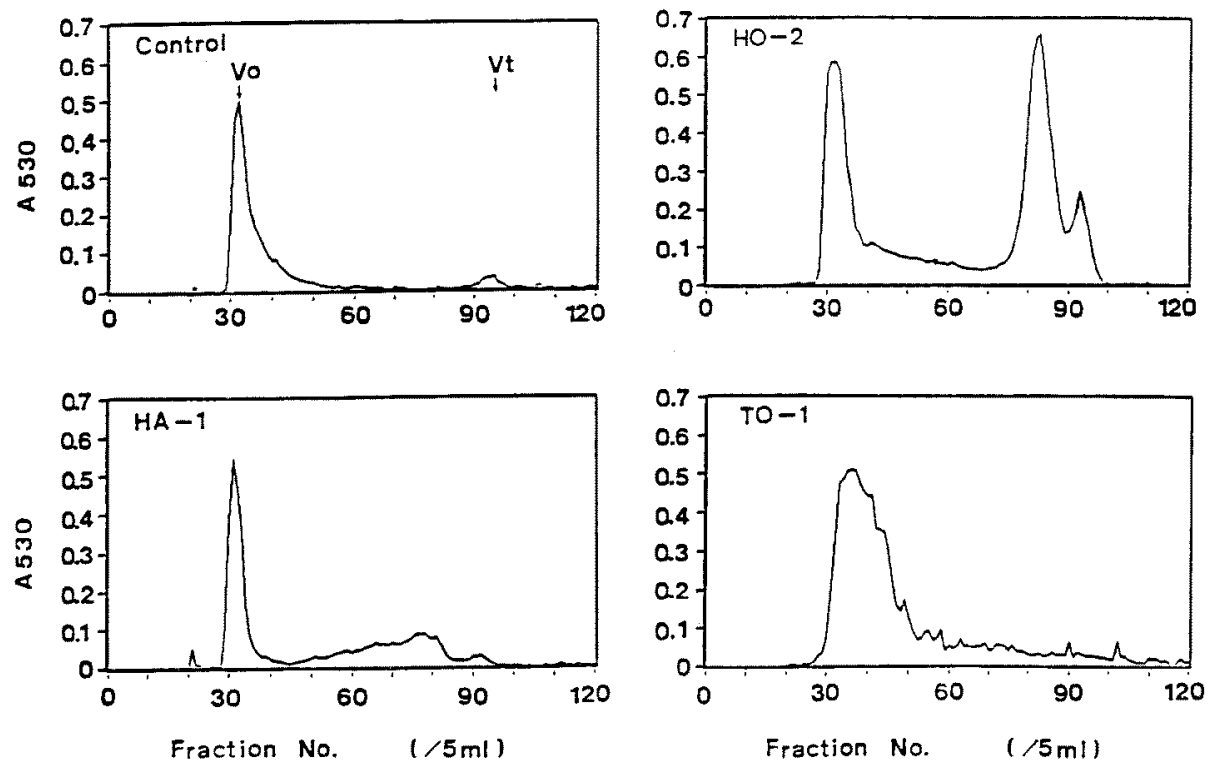

Fig. 5. Gel filtration chromatograms of saccharides released into the S-medium of 4 samples, an axenic control and 3 LDB (HA-1, HO-2, and TO-1) after incubation.

Filtration conditions: gel Sephacryl S-300; column size $2.6 \times 95 \mathrm{~cm}$; eluent, $25 \mathrm{mM}$ sodium phosphate $(\mathrm{pH} 7.0$ ); flow rate, $0.6-1.0 \mathrm{ml} / \mathrm{min}$; sample volume, $5 \mathrm{ml}$; fraction volume, $5 \mathrm{ml}$. Vo: void volume. $\mathrm{Vt}$ : total volume.

Table 6. Numbers of isolates having a frond decomposing ability and an alginate-degrading ability

\begin{tabular}{lrrr} 
Frond-decomposing & $H /+^{* *}$ & 48 & 14 \\
ability & $-* * *$ & 1 & 26 \\
\hline
\end{tabular}

* Determined by Ando-Inoue's method.

Frond decomposing ability is positive in either (S or NS)

Frond decomposing ability is negative in both (S and NS) media.

$$
12
$$


as alginate and cellulose. To make clear it that the polysaccharides were actually degraded, saccharides released from the frond piece into the S-medium during the decomposition test were analyzed by gel filtration. Elution patterns obtained from three different LDB strains (HA-1, HO-2, and TO-1) which possessed \# decomposing ability and were characterized to Vibrio group are shown in Fig. 5 together with that of an axenic control. Only a single peak appeared at the void volume in the elution pattern of the control experiment, but some different peaks were observed in those of the three strains. The pattern of HA-1 had a broad peak corresponding from middle to low molecular weight substances. That of $\mathrm{HO}-2$ is characterized by two large peaks of lower molecular weight substances. A relatively large peak of high molecualr weight substance was observed in the case of TO-1. The viscosity of the S-medium incubated with TO-1 increased markedly according to the accumulation of the high molecular polysaccharides in the medium. These findings implied the degradation of algal polysaccharides by the LDB during the frond decomposition, since no such peak was observed in the cases of nonLDB strains. Although the decomposed and fragmented fronds were not macroscopically discernable from each other, the elution patterns showed a wide variation.

\section{Discussion}

Many kinds of bacteria able to utilize algal substrates such as alginate, cellulose, laminaran, and mannitol have been found on the surface of fronds of macroalgae ${ }^{1-3)}$ and are considered to be involved in the decay process of algal fronds. But it was not clear which kind of bacteria played an important role for the direct decomposition of macroalgal fronds, by which frond tissue is softened, fragmentated, and carried into the detrital food chain in the marine environment. This is partily attributable to the fact that there was no good method for estimating the microbial decomposing ability for algal fronds. Measuring the physical strength of frond pieces with the use of a rheometer, we found bacteria which had the ability to decrease the cutting strength of frond tissue during incubation, and called them LDB. The present method was considered to be effective because the frond pieces incubated with LBD showed a definite decrease in cutting strength less than $200 \mathrm{~g}$ (Fig. 3; and about $90 \%$ of the LDB were easily discerned from non-LDB. The LDB were isolated from 10 did out of 11 locations, even from the sea where Laminaria did not vegetate, suggesting that $\mathrm{LDB}$ is commonly distributed in the waters. No LDB was found at location Niigata, and only one at location Saeki. This might be related to the fact that salinity was as low as 24\%o (Table 1). Bacteria forming hollows on Laminaria powder-enriched agar plates did not always decrease the cutting strength of the Laminaria frond pieces. This may be due to the fact that hollows could be made by the degradation of agar or some other low molecular compounds which did not participate in the physical strength of the frond pieces. Nutrition enrichment to the culture medium had little influence on the assessment of the frond-decomposing ability (Table 2), but rapid decomposition was often observed in the NS-medium.

Hollohan et al. ${ }^{\text {3) }}$ reported that Vibrio dominated on the decaying fronds of a brown alga. Alginatedegrading bacteria isolated so far were often also identified as genus Vibrio. ${ }^{\theta, 14)}$ With the present result that the major part of the LDB isolated was characterized as Vibrio (Group I in Table 5), it is confirmed that this kind of bacteria plays an important role in the microbial decomposition processes of macroalgal fronds in the marine environment. It was also found that LDB commonly possessed an alginate-degrading activity (Table 6), but degrading activities against other kinds of algal polysaccharides remain to be studied. It is, however, clear that the frond decomposition detected by the use of a rheometer was due to the degradation of polysaccharides. Though components in each peak were not identified, the peak which appeared at the position of void volume in case of the medium of TO-1 was thought to represent that of alginate compounds released by alginate-degrading enzymes. This was because its molecular weight was over $10^{4}$ and its total amount accounted for approximately $10 \%$ of the Laminaria frond pieces by dry weight (on the basis of sodium alginate). As for the other strains of $\mathrm{LDB}$, the information about the frond decomposing mechanism is scanty. However, when we remember the significance of seaweed decomposition in the natural environment as a source of nutrients for offshore areas, ${ }^{22}$ it is an interesting finding that the saccharides released from frond tissue, though under experimental conditions, would differ greatly according to the kind of bacteria involved in the frond decomposition. 


\section{Acknowledgments}

We express our gratitude to Dr. B. Kimura, Dr. K. Kato, Dr. A. Sugiyama, Dr. A. Shiomoto, Mr. A. Fujii, Mr. H. Saito, Mr. S. Yamada, Mr. K. Kimoto, and Mr. S. Itakura for helping us in seawater sampling. This work was partly supported by a grant (Biomass conversion program) from the Research Council of the Ministry of Agriculture, Forestry and Fisheries, Japan.

\section{References}

1) R. A. Laycock: The detrital food chain based on seaweeds. I. Bacteria associated with the surface of I aminaria fronds. Mar. Biol., 25, 223-231 (1974).

2) M. R. Kirchner: Microbial degradation of North Sea macroalgae: Field and laboratory studies. Bot. Mar, 32, 241-252 (1989).

3) B. T. Hollohan, P. E. Dabinett, and J. A. Gow: Bacterial succession during biodegradation of the kelp Alaria esculenta (L.) Greville. Can. J. Microbiol., 32, 505-512 (1986).

4) S. A. Waksman, C. L. Carey, and M. C. Allep: Bacteria decomposing alginic acid. J. Bact., 28, (1934).

5) S. A. Waksman and M. C. Allen: Decomposition of polyuronides by fungi and bacteria. II. Decomposition of alginic acid by bacteria and formation of the enzyme alginase. J. Am. Chem. Soc., 56, 2701-2705 (1934).

6) P. Kooiman: Enzymic hydrolysis of alginic acid. Biochemica et Biophysia Acta, 13, 338-340 (1954).

7) K. Inove and $Y$. Ando: Decomposition of alginic acid by microorganisms. Part I. Decomposition of alginic acid by Aerobacter aerogenes type $Y-11$ strain and adaptive formation of alginase. Nippon Nogeikagaku Kaishi, 30, 742-746 (1956) (in Japanese).

8) K. Inoue: Decomposition of alginic acid by microorganisms. Part II. On the "alginase" action of $A$. aerogenes $Y-11$. Nippon Nogeikagaku Kaishi, 31, 798-801 (1957) (in Japanese).

9) Y. Ando and K. Inoue: Decomposition of alginic acid by microorganisms-IV, on the Vibrio-type bacteria, newly iso- lated from the decaying Laminaria. Nippon Suisan Gakkaishi, 27, 339-341 (1961).

10) $Y$. Ando and $K$. Inoue: Decomposition of alginic acid by microorganisms-VI. on the modes of action of two alginases. Nippon Suisan Gakkaishi, 31, 552-557 (1965).

11) K. Yamaguchi: Studies on the alginic acid destroying bacteria Part I. On the identification of one isolated strain and its alginase. Nippon Nogeikagaku Kaishi, 32, 483-486 (1958) (in Japanese).

12) R.S. Doubet and R.S. Quatrano: Isolation of marine bacteria capable of producing specific lyases for alginate degradation. Appl. Env. Microbiol., 44, 754-756 (1982).

13) T. Romeo and J.F. Preston III: Depolymerization of alginate by an extracellular alginate lyase from a marine bacteria: Substrate specificity and accumulation of reaction products. Blochemistry, 25, 8391-8396 (1986).

14) M. Kitamikado, C. H. Tseng, T. Aoki, K. Yamaguchi, and T. Araki: Isolation of bacteria capable of producing alginatedegrading enzyme from natural environment. Nippon Suisan Gakkaishi, 55, 709-713 (1989).

15) T. Sawabe, Y. Ezura, and T. Kimura: Characterization of an alginolytic marine bacterium from decaying Rishiri-kombu Laminaria japonica var. ochotensis. Nippon Suisan Gakkaisht, 58, 141-145 (1992).

16) C. H. Tseng, K. Yamaguchi, and M. Kitamikado: Two types of alginate lyase from a marine bacterium Vibrio $\mathrm{sp}$. AL-9. Nippon Suisan Gakkaishi, 58, 743-749 (1992).

17) K. H. Mann: Seaweeds: their productivity and strategy for growth. Sctence, 182, 975-981 (1973).

18) T. Sekine: Studies of softening and decomposition of seaweeds (Phaeophyceae) by microorganisms and their utilization 1. On general characteristics of bacillus. Nippon Suisan Gakkaishi, 16, 4345 (1951).

19) U. Simidu: In "Methods on marine microbiology" (ed. by H. Kadota and N. Taga), Gakkaishuppan Center, Tokyo, 1985, pp. 228-233 (in Japanese).

20) E. Leifson: Determination of carbohydrate metabolism of marine bacteria. J. Bact., 85, 1183-1184 (1963).

21) T. Bitter and H. M. Muir: A modified uronic acid carbazole reaction. Anal. Biochem., 4, 330 (1962).

22) A. I. Robertson and J. A. Hansen: Decomposing seaweed: a nuisance or a vital link in coastal food chains ? CSIRO Division of Fisheries and Oceanography Report 1980-1981, $75-83$ (1982) 